\title{
Time to think beyond door to balloon time: significance of total ischemic time in STEMI
}

\author{
Sanam Khowaja*, Salik Ahmed, Rajesh Kumar, Jehangir Ali Shah, Kamran Ahmed Khan, Naveed Ullah Khan, \\ Tahir Saghir, Syed Nadeem Hasan Rizvi, Nadeem Qamar and Musa Karim
}

\begin{abstract}
Background: Significance of total ischemic time (TIT) in the context of ST-segment elevation myocardial infarction (STEMI) is still controversial. Therefore, in this study, we have evaluate the association of TIT with immediate outcomes in STEMI patients in whom recommended door to balloon (DTB) time of less than 90 min was achieved.

Results: A total of 5730 patients were included in this study, out of which $80.9 \%$ were male and median age was 55 [61-48] years. The median DTB was observed to be 60 [75-45] min and onset of chest pain to emergency room (ER) arrival time was 180 [300-120] min. Prolonged TIT was associated with poor pre-procedure thrombolysis in myocardial infarction (TIMI) flow grade $(p=0.022)$, number of diseased vessels $(p=0.002)$, use of intra-aortic balloon pump $(p=0.003)$, and in-hospital mortality $(p=0.002)$. Mortality rate was $4.5 \%, 5.7 \%$, and $7.8 \%$ for the patients with TIT of $\leq 120 \mathrm{~min}, 121$ to $240 \mathrm{~min}$, and $>240 \mathrm{~min}$, respectively. Thirty days' risk of mortality on TIMI score was $4.97 \pm 7.09 \%$, $5.01 \pm 6.99 \%$, and $7.12 \pm 8.64 \%$ for the patients with TIT of $\leq 120 \mathrm{~min}, 121$ to $240 \mathrm{~min}$, and $>240 \mathrm{~min}$, respectively.
\end{abstract}

Conclusions: Prolonged total ischemic was associated with higher in-hospital mortality. Therefore, TIT can also be considered in the matrix of focus, along with DTB time and other clinical determinants to improve the survival from STEMI.

Keywords: ST-segment elevation myocardial infarction, Total ischemic time, Door to balloon, Primary percutaneous coronary intervention, In-hospital outcomes

\section{Background}

Both American College of Cardiology (ACC)/American Heart Association (AHA)/Society for Cardiovascular Angiography and Interventions (SCAI) and European Society of Cardiology (ESC) guidelines recommend primary percutaneous coronary intervention (PCI) for early reperfusion of the ST-segment elevation myocardial infarction (STEMI) for patients presenting to emergency room (ER) within $12 \mathrm{~h}$ of onset of chest pain [1, 2]. The reperfusion therapy recovers maximum myocardial damage if performed within initial few hours of chest pain and with every passing hour the recovery decreases sharply [3]. Percutaneous intervention has received

*Correspondence: sanam.khowaja2@gmail.com

National Institute of Cardiovascular Diseases (NICVD), Karachi, Pakistan preference over pharmacologic therapy for reperfusion of STEMI patients due to its ability to rapidly restore the patency of affected artery [4]. Hence, the ER arrival to the ballooning time, known as door to balloon (DTB) time, gained immense importance among the cardiologist and is considered to be the most important quality indicator for primary PCI [5]. Emphasis on reduction of DTB time was made in the management guidelines of STEMI and optimal DTB time of $\leq 90 \mathrm{~min}$ is recommended $[1,2,6]$.

However, less attention was given to the other delays in the timeline of STEMI such as time between onset of chest and PCI capable hospital arrival [5]. The total ischemic time (TIT), time between onset of chest and ballooning or device activation, can be a more strong prognostic marker than DTB time as increase in microvascular obstruction area is reported to be associated with prolonged ischemia [7]. TIT was reported to be an 
independent predictor of infarct size and short and long term mortality in patients with STEMI $[4,5,8,9]$. The optimal prognostic cutoff for TIT is debatable. It was reported that the reduction in DTB time has no added advantage in the late presented STEMI patients [7, 10]; therefore, the efforts of DTB time reduction failed to decrease the mortality rate of STEMI patients $[11,12]$. Various factors have been reported to play role in prolongation of TIT such as unawareness and patients failure to recognize cardiac symptoms, unavailability of attendant, transportation, finance, and nearby facility [9].

Consequently, it is well established that DTB time is very important in identifying in-hospital outcomes and long term morbidity and mortality in the STEMI; however, significance of total ischemic time in STEMI patients is still debatable. Moreover, there is paucity of local data which further enlightened its significance for further research. Therefore, the aim of this study was to evaluate the association of TIT with immediate outcomes in STEMI patients in whom recommended DTB time of less than 90 min was achieved.

\section{Methods \\ Study population}

This study was conducted on selected patients from a prospectively collected institutional data registry. A single center hospital-based registry was established in January 2015 at the National Institute of Cardiovascular Diseases (NICVD), Karachi, Pakistan. Prior to inclusion, informed consent was taken explaining purpose and benefits of the study. Collected data were accessible to authorized personnel only and confidentiality was maintained at all stage of extraction of data and results. NICVD is one of the largest public sector tertiary care cardiac hospital and training center in Pakistan where primary PCI is being offered as the standard treatment $24 / 7$ since 2010. All the procedures were performed as per the ACC/AHA guidelines by consultant cardiologist with experience of more than 5 years. Any contraindication to dual antiplatelet therapy was ruled out by taking brief history of the patient and an echocardiographic screening was done to assess any potential mechanical complications.

\section{Study variables}

Study was commenced after approval of the institutional ethical review committee. In this study, we included patients presented within $12 \mathrm{~h}$ of onset of chest pain, diagnosed with STEMI and underwent primary PCI during 1st June 2015 to 28th February 2018. Patients with prior history of any cardiac related surgery or intervention and patients with DTB time of $>90 \mathrm{~min}$, due to any reason, were also excluded from the study. The TIT was measured on hospital arrival and was defined as the duration (in minutes) between onset of chest pain and ER arrival plus the duration (in minutes) between ER arrival and device activation. The DTB time was defined as the duration (in minutes) between ER arrival and device activation. Variables extracted from the registry were patient's demography, risk profile, intra procedural characteristics, post procedural components, presenting KILLIP class, time variables, and in-hospital mortality.

\section{Statistical analysis}

Patients were grouped into three based on TIT: Group 1, TIT $\leq 120 \mathrm{~min}$; Group 2, TIT between 121 to $240 \mathrm{~min}$; and Group 3, TIT $>240 \mathrm{~min}$. All the variables were entered into the IBM SPSS Statistics for Windows, Version 21.0. (IBM Corp., Armonk, NY, US) for data analysis. Frequency and percentages were calculated for all the categorical variables. Continuous variables were assessed for normality of distribution by applying KolmogorovSmirnov normality test and appropriate summary measure such as mean \pm standard deviation (SD) or median [interquartile range (IQR)] were computed. Records with missing information regarding disease anatomy, in-hospital outcome, and other study variables were excluded from the analysis. The receiver operating characteristic (ROC) curve analysis was performed and area under the curve (AUC), optimal prognostic cutoff value of TIT and its sensitivity and specificity were calculated. Chi-square test was performed to assess the differences in various characteristics and outcomes by different TIT groups. Multivariable logistic regression analysis was performed to assess the predictors of mortality taken demographic characteristics (such as gender and age), co-morbid conditions (such as diabetes, hypertension, smoking, and positive family history of coronary artery diseases), and TIT as explanatory variables based on results of univariate comparison and clinical judgment and odds ratio (OR) and 95\% confidence interval (CI) were reported. Throughout the analysis, $p \leq 0.05$ was the criteria for statistical significance.

\section{Results}

A total of 5730 patients were selected, of them 4637 (80.9\%) were males and median age was $55(61-48)$ years. The median of DTB was observed to be $60(75-45) \mathrm{min}$ and chest pain ER arrival time was 180 (300-120) min. A total of 2978 (52\%) patients were hypertensive, 1712 (29.9\%) diabetic, 1636 (28.6\%) smokers, and 263 (4.6\%) had family history of CAD. Prolonged TIT was found to be associated with age $(p<0.001)$, gender $(p<0.001)$, diabetes $(p=0.039)$, and hypertension $(p=0.021)$. Baseline clinical and demographic characteristics stratified by the total ischemic time are presented in Table 1. 
Table 1 Baseline clinical and demographic characteristics stratified by the total ischemic time

\begin{tabular}{|c|c|c|c|c|c|}
\hline \multirow[t]{2}{*}{ Characteristics } & \multirow[t]{2}{*}{ Total } & \multicolumn{3}{|c|}{ Total ischemic time (min) } & \multirow[t]{2}{*}{$p$ value } \\
\hline & & Up to 120 & 121 to 240 & More than 240 & \\
\hline Total & 5730 & $418(7.3 \%)$ & 2199 (38.4\%) & $3113(54.3 \%)$ & - \\
\hline \multicolumn{6}{|l|}{ Age (years) } \\
\hline Median [IQR] & $55[61-48]$ & $52.5[60-45]$ & 55 [60-47] & 55 [62-48] & $<0.001^{*}$ \\
\hline Up to 40 years & $608(10.6 \%)$ & $53(12.7 \%)$ & $234(10.6 \%)$ & $321(10.3 \%)$ & \multirow[t]{4}{*}{$0.025^{*}$} \\
\hline 41 to 50 years & $1675(29.2 \%)$ & $139(33.3 \%)$ & $657(29.9 \%)$ & $879(28.2 \%)$ & \\
\hline 51 to 60 years & $2004(35 \%)$ & $147(35.2 \%)$ & 767 (34.9\%) & $1090(35 \%)$ & \\
\hline$>60$ years & $1443(25.2 \%)$ & 79 (18.9\%) & $541(24.6 \%)$ & $823(26.4 \%)$ & \\
\hline \multicolumn{6}{|l|}{ Gender } \\
\hline Male & 4637 (80.9\%) & $369(88.3 \%)$ & $1832(83.3 \%)$ & $2436(78.3 \%)$ & \multirow[t]{2}{*}{$<0.001^{*}$} \\
\hline Female & $1093(19.1 \%)$ & $49(11.7 \%)$ & 367 (16.7\%) & 677 (21.7\%) & \\
\hline \multicolumn{6}{|l|}{ Medical history } \\
\hline Diabetes & $1712(29.9 \%)$ & $123(29.4 \%)$ & $616(28 \%)$ & $973(31.3 \%)$ & $0.039^{*}$ \\
\hline Hypertension & $2978(52 \%)$ & $195(46.7 \%)$ & $1123(51.1 \%)$ & $1660(53.3 \%)$ & $0.021^{*}$ \\
\hline Smoke & $1636(28.6 \%)$ & $122(29.2 \%)$ & 647 (29.4\%) & $867(27.9 \%)$ & 0.438 \\
\hline Family history & $263(4.6 \%)$ & $20(4.8 \%)$ & $89(4 \%)$ & $154(4.9 \%)$ & 0.298 \\
\hline \multicolumn{6}{|l|}{ KILLIP class } \\
\hline I & $5070(88.5 \%)$ & $376(90 \%)$ & 1977 (89.9\%) & $2717(87.3 \%)$ & \multirow[t]{4}{*}{$0.009^{*}$} \\
\hline$\|$ & $287(5 \%)$ & $16(3.8 \%)$ & $111(5 \%)$ & $160(5.1 \%)$ & \\
\hline III & $159(2.8 \%)$ & $9(2.2 \%)$ & $43(2 \%)$ & $107(3.4 \%)$ & \\
\hline IV & $214(3.7 \%)$ & $17(4.1 \%)$ & $68(3.1 \%)$ & $129(4.1 \%)$ & \\
\hline \multicolumn{6}{|c|}{ Symptom onset to hospital arrival time (min) } \\
\hline Median [IQR] & $180[300-120]$ & $60[60-30]$ & 120 [160-120] & $283[385-240]$ & $<0.001^{*}$ \\
\hline \multicolumn{6}{|c|}{ Door to balloon time (min) } \\
\hline Median [IQR] & $60[75-45]$ & $45[55-37]$ & $55[71-45]$ & 65 [75-49] & $<0.001^{*}$ \\
\hline \multicolumn{6}{|c|}{ Total ischemic time (min) } \\
\hline Median [IQR] & 255 [355-180] & 101 [110-85] & $185[213-165]$ & $341[446-285]$ & $<0.001^{*}$ \\
\hline
\end{tabular}

Angiographic and procedural characteristics stratified by the TIT are presented in Table 2. Prolonged TIT was associated with pre-procedure TIMI flow $(p=0.022)$, number of diseased vessels $(p=0.002)$, use of IABP $(p=0.003)$, and side branch involvement $(p=0.008)$.

Post-procedure TIMI flow grade 0 was observed in $94(1.6 \%)$, I in $47(0.8 \%)$, II in 228 (4.0\%), and III in 5361 (93.6\%) patients. In-hospital mortality rate was $388(6.8 \%)$ and mortality rate was $4.5 \%, 5.7 \%$, and $7.8 \%$ for the patients with TIT of $\leq 120 \mathrm{~min}, 121$ to $240 \mathrm{~min}$, and $>240 \mathrm{~min}$, respectively. Thirty days risk of mortality on TIMI score was $2.2 \%$ (4.4-1.6\%), 2.2\% [4.4-1.6\%], and 4.4\% [7.3-2.2\%] for the patients with TIT of $\leq 120 \mathrm{~min}$, 121 to $240 \mathrm{~min}$, and $>240 \mathrm{~min}$, respectively. The optimal cutoff value of TIT based on ROC curve analysis was found to be $297 \mathrm{~min}$ (rounded of to $300 \mathrm{~min}$ ), with sensitivity of $50.26 \%$ and specificity of $63.33 \%$. ROC curve and in-hospital mortality rate stratified by the TIT are presented in Fig. 1.
Multivariable logistic regression analysis for in-hospital mortality is presented in Table 3. On multivariable logistic regression, female gender $(\mathrm{OR}=1.29, p=0.046)$, age $(\mathrm{OR}=1.04, p<0.001)$, diabetes $(\mathrm{OR}=1.91, p<0.001)$, and TIT $(\mathrm{OR}=1.05, p<0.001)$ were significant predictors of in-hospital mortality.

\section{Discussion}

In this study, our aim was to assess the effect of TIT on mortality of STEMI patients in whom the recommended DTB time of $<90 \mathrm{~min}$ was achieved. We found that TIT is a good prognostic marker, mortality rate is linearly associated with TIT and every delay of an hour after onset of chest pain increases risk of mortality nearly by $5 \%(\mathrm{OR}=1.05)$. The optimal prognostic cutoff value for the TIT was 300 min, after which the risk of mortality increases exponentially. In our setup, more than half (54.3\%) of the STEMI patients had TIT of more than 
Table 2 Angiographic and procedural characteristics stratified by the total ischemic time

\begin{tabular}{|c|c|c|c|c|c|}
\hline \multirow[t]{2}{*}{ Characteristics } & \multirow[t]{2}{*}{ Total } & \multicolumn{3}{|c|}{ Total ischemic time ( $\mathrm{min})$} & \multirow[t]{2}{*}{$p$ value } \\
\hline & & Up to 120 & 121 to 240 & More than 240 & \\
\hline Total & 5730 & $418(7.3 \%)$ & $2199(38.4 \%)$ & $3113(54.3 \%)$ & - \\
\hline \multicolumn{6}{|l|}{ Pre-procedural TIMI flow } \\
\hline No flow & $3272(57.1 \%)$ & $240(57.4 \%)$ & $1244(56.6 \%)$ & 1788 (57.4\%) & \multirow[t]{4}{*}{$0.022^{*}$} \\
\hline I & $1013(17.7 \%)$ & 70 (16.7\%) & $402(18.3 \%)$ & $541(17.4 \%)$ & \\
\hline$\|$ & $863(15.1 \%)$ & $66(15.8 \%)$ & $297(13.5 \%)$ & $500(16.1 \%)$ & \\
\hline III & $582(10.2 \%)$ & $42(10 \%)$ & $256(11.6 \%)$ & $284(9.1 \%)$ & \\
\hline \multicolumn{6}{|c|}{ Number of vessels involved } \\
\hline None & $14(0.2 \%)$ & $0(0 \%)$ & $7(0.3 \%)$ & $7(0.2 \%)$ & \multirow[t]{4}{*}{$0.002^{*}$} \\
\hline Single vessel (SVD) & $2278(39.8 \%)$ & $177(42.3 \%)$ & 938 (42.7\%) & $1163(37.4 \%)$ & \\
\hline Multi vessels (MVD) & $3430(59.9 \%)$ & $240(57.4 \%)$ & $1249(56.8 \%)$ & $1941(62.4 \%)$ & \\
\hline Left main (LM) & $8(0.1 \%)$ & $1(0.2 \%)$ & $5(0.2 \%)$ & $2(0.1 \%)$ & \\
\hline \multicolumn{6}{|l|}{ Infarct related artery } \\
\hline None & $15(0.3 \%)$ & $0(0 \%)$ & $7(0.3 \%)$ & $8(0.3 \%)$ & \multirow[t]{8}{*}{0.884} \\
\hline LAD & 3097 (54\%) & $242(57.9 \%)$ & $1184(53.8 \%)$ & $1671(53.7 \%)$ & \\
\hline Right coronary artery & $1828(31.9 \%)$ & $121(28.9 \%)$ & $712(32.4 \%)$ & 995 (32\%) & \\
\hline Left circumflex & $660(11.5 \%)$ & $48(11.5 \%)$ & $244(11.1 \%)$ & $368(11.8 \%)$ & \\
\hline Ramus & $27(0.5 \%)$ & $2(0.5 \%)$ & $10(0.5 \%)$ & $15(0.5 \%)$ & \\
\hline Left main & $26(0.5 \%)$ & $3(0.7 \%)$ & $10(0.5 \%)$ & $13(0.4 \%)$ & \\
\hline Diagonal & $64(1.1 \%)$ & $2(0.5 \%)$ & $27(1.2 \%)$ & $35(1.1 \%)$ & \\
\hline Others & $13(0.2 \%)$ & $0(0 \%)$ & $5(0.2 \%)$ & $8(0.3 \%)$ & \\
\hline \multicolumn{6}{|l|}{ Side branch involvement } \\
\hline Yes & $645(11.3 \%)$ & $65(15.6 \%)$ & $227(10.3 \%)$ & $353(11.3 \%)$ & \multirow[t]{2}{*}{$0.008^{*}$} \\
\hline No & $5085(88.7 \%)$ & $353(84.4 \%)$ & 1972 (89.7\%) & $2760(88.7 \%)$ & \\
\hline \multicolumn{6}{|c|}{ Left ventricular dysfunction } \\
\hline Yes & $3239(56.5 \%)$ & $232(55.5 \%)$ & $1210(55 \%)$ & $1797(57.7 \%)$ & \multirow[t]{2}{*}{0.134} \\
\hline No & $2491(43.5 \%)$ & $186(44.5 \%)$ & $989(45 \%)$ & $1316(42.3 \%)$ & \\
\hline \multicolumn{6}{|l|}{ Thrombus grading } \\
\hline No & 409 (7.1\%) & $28(6.7 \%)$ & $166(7.5 \%)$ & 215 (6.9\%) & \multirow[t]{6}{*}{0.346} \\
\hline Possible & $591(10.3 \%)$ & $43(10.3 \%)$ & $217(9.9 \%)$ & $331(10.6 \%)$ & \\
\hline Small & $552(9.6 \%)$ & $35(8.4 \%)$ & $220(10 \%)$ & $297(9.5 \%)$ & \\
\hline Moderate & $883(15.4 \%)$ & $60(14.4 \%)$ & $345(15.7 \%)$ & $478(15.4 \%)$ & \\
\hline Large & $746(13 \%)$ & $53(12.7 \%)$ & $315(14.3 \%)$ & $378(12.1 \%)$ & \\
\hline Total & $2549(44.5 \%)$ & $199(47.6 \%)$ & $936(42.6 \%)$ & $1414(45.4 \%)$ & \\
\hline \multicolumn{6}{|c|}{ Intra-aortic balloon pump (IABP) used } \\
\hline Yes & $193(3.4 \%)$ & $10(2.4 \%)$ & $55(2.5 \%)$ & $128(4.1 \%)$ & \multirow[t]{2}{*}{$0.003^{*}$} \\
\hline No & $5537(96.6 \%)$ & $408(97.6 \%)$ & $2144(97.5 \%)$ & 2985 (95.9\%) & \\
\hline \multicolumn{6}{|l|}{ Export catheter } \\
\hline Yes & $1887(32.9 \%)$ & $148(35.4 \%)$ & $736(33.5 \%)$ & $1003(32.2 \%)$ & \multirow[t]{2}{*}{0.339} \\
\hline No & $3843(67.1 \%)$ & $270(64.6 \%)$ & $1463(66.5 \%)$ & $2110(67.8 \%)$ & \\
\hline
\end{tabular}

LAD left anterior descending artery, TIMI thrombolysis in myocardial infarction

*Significant at $5 \%$

$4 \mathrm{~h}$. Prolonged TIT was observed to be associated with age and female gender, and patients with prolonged TIT had low TIMI flow grades, multivessel involvement, and increased use of IABP.
The prognostic importance of TIT is well documented by various studies in the past. De Luca et al. [8] reported shorter TIT in patients with successful reperfusion and every half an hour delay was reported to be associated with an increased relative risk of mortality at 1 year. 


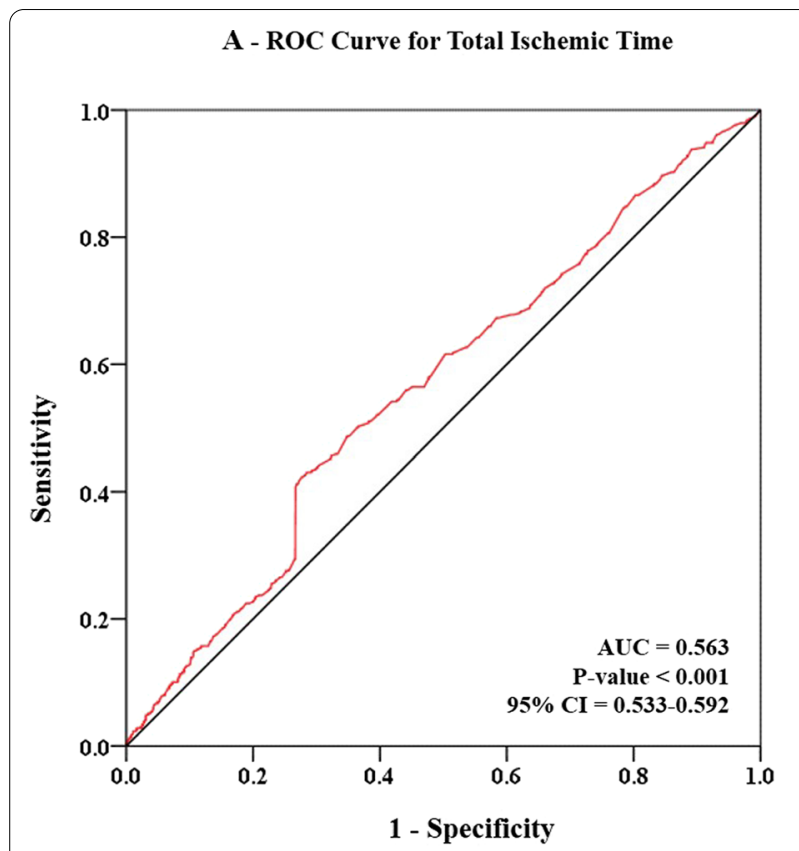

B - In-hospital Mortality Rate by Total Ischemic Time

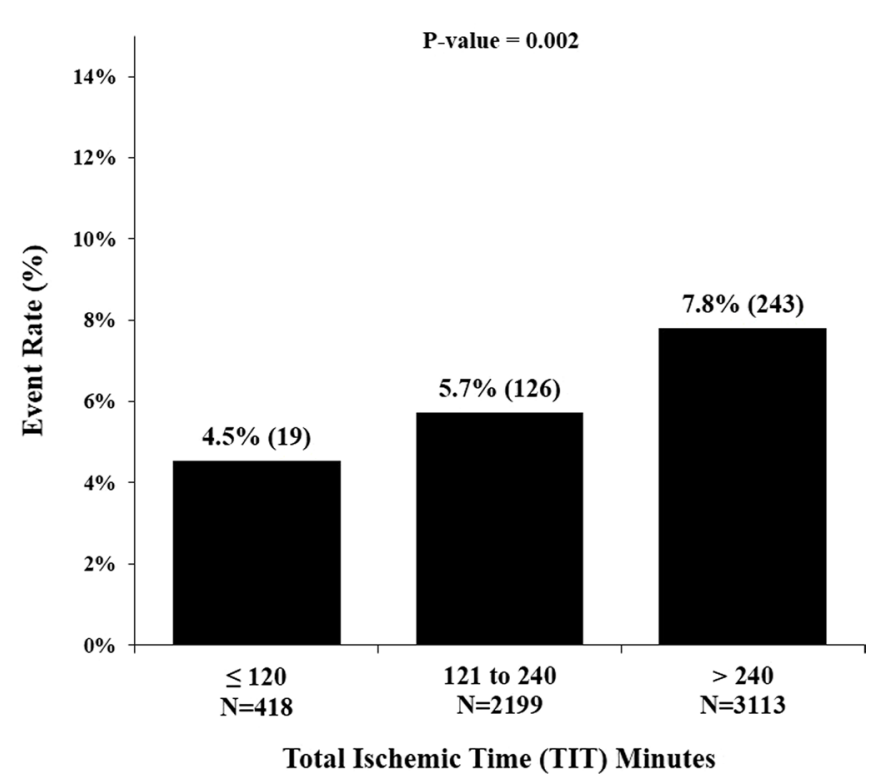

Fig. 1 A Receiver operating characteristic (ROC) curve and $\mathbf{B}$ in-hospital mortality rate stratified by the total ischemic time

Table 3 Multivariable logistic regression analysis for in-hospital mortality

\begin{tabular}{llcc}
\hline Predictors & Odds ratio (OR) & $\mathbf{9 5 \%} \mathbf{C l}$ for OR & $\boldsymbol{p}$ value \\
\hline Age (years) & 1.04 & $1.03-1.05$ & $<0.001^{*}$ \\
Female gender & 1.29 & $1-1.65$ & $0.046^{*}$ \\
Diabetic & 1.91 & $1.54-2.37$ & $<0.001^{*}$ \\
Hypertensive & 1.08 & $0.87-1.34$ & 0.499 \\
Smoker & 0.89 & $0.68-1.16$ & 0.376 \\
Positive family history & 1.15 & $0.7-1.89$ & 0.588 \\
Total ischemic time (h) & 1.05 & $1.02-1.07$ & $<0.001^{*}$
\end{tabular}

Dependent variable in-hospital mortality [yes]

Hosmer and Lemeshow Test (chi-square $=5.876, d f=8, p=0.661$ )

$O R$ odds ratio, $\mathrm{Cl}$ confidence level

*Significant at $5 \%$ level of significance

Khalid et al. [9], in an editorial, highlighted that the myocardium gets injured with every passing second; therefore, TIT should be targeted in STEMI patients to reduce the mortality rate. Prolonged TIT is a problem not specific to a certain geography or population, it exists across the world with varying degrees of intensity. For example, a study conducted in Australian population by Chandrasekhar et al. [13] reported prolonged TIT ( $>240 \mathrm{~min}$ ) for more than one third $(34.2 \%)$ of the STEMI patients. They also reported that TIT was strongly correlated and found as an independent predictor of major adverse cardiovascular events (MACE). An Indian study by
Doddipalli et al. [14] reported that lack of awareness and time taken by patients in recognizing symptom were the main contributors to prolonged TIT and the mean TIT was reported to be significantly higher among expired patients, $(8.0 \pm 3.6 \mathrm{~h}$ vs. $6.2 \pm 2.8 \mathrm{~h} ; p<0.05)$ as compared to alive patients. Results from a Korean nationwide registry by Kim et al. [15] observed that shorter $(<3 \mathrm{~h})$ TIT was associated with reduced risk of mortality at one month. According to Koifman et al. [16], utilization of mobile coronary care unit (CCU) is an effective strategy to reduce TIT which subsequently reduced 1-year mortality among STEMI patients. Similarly, Solhpour et al. [5] conducted a study at a STEMI center in US revealed TIT as a better predictor of mortality than DTB time. They documented that TIT was more than $4 \mathrm{~h}$ for nearly one-third of the STEMI patients and reported to be a good predictor of infarct size and 30-day mortality than DTB time.

Hence, most of the studies addressing the impact of TIT in STEMI management, including our study, agreed to the fact that TIT holds prognostic utility. In fact, in a number of cases, it proved to be a better predictor of mortality (immediate, short, and long term) than DTB time $[5,8,9,13-16]$. One of underlying mechanism of increased mortality with prolongation of ischemic time, as reported in animal model study, is that infarct size significantly affects myocardial tissue and keeps on damaging with every passing second of ischemic time [17-19]. Hence, even with optimal reperfusion (primary PCI), 
prolonged ischemic time may cause higher mortality and less myocardial salvage $[8,9]$. Decrease in DTB time is unlikely to render the ultimate desired reduction in mortality after primary PCI [13], and therefore, it should not be considered the sole quality indicator [15]. Therefore, the matrix of focus has to be shifted, along with strategies in place to reduce DTB time, TIT also need to bring to light in order to improve the survival from STEMI.

\section{Limitation}

Single center registry-based study and non-randomized nature of the design are key limitations of this study. Secondly, time of onset of chest pain was noted in the ER based on patient or attendants recall, which may have some over or understating. Even though TIT was observed to be an independent predictor of in-hospital mortality, but low predictive value of ischemic time warranted further investigation for the potential effect of confounding factors.

\section{Conclusions}

Prolonged TIT was associated with higher in-hospital mortality of STEMI patients in whom the recommended DTB was achieved. Although predictive value of TIT was low, but it was found to be an independent predictor of mortality and risk of mortality increases nearly by $5 \%$ with every passing hour of TIT. This could be achieved through a rigorous Emergency Management System (EMS) and meticulous patient awareness programs in developing countries.

\section{Abbreviations}

STEMI: ST elevation myocardial infarction; DTB: Door to balloon; TIT: Total ischemic time; PCI: Percutaneous coronary intervention; ER: Emergency room; EMS: Emergency Management System.

\section{Acknowledgements \\ The authors wish to acknowledge the support of the staff members of the Clinical Research Department of the National Institute of Cardiovascular Diseases (NICVD) Karachi, Pakistan.}

\section{Authors' contributions}

SK, SA, TS, MK, SNHR contributed to the concept and design of study, MK, SK, SA, NUK, RK, JAS, KAK contributed to the analysis and interpretation of data, SK, SA, MK, RK, JAS, KAK, and NUK collected data and drafted the manuscript, and TS, SNHR, and NQ critically analysed for content. All authors read and approved the final manuscript.

\section{Funding}

Not applicable.

\section{Availability of data and materials}

Data and material will be available upon request.

\section{Declarations}

\section{Ethics approval and consent to participate}

This study was approval by the ethical review committee of the National Institute of Cardiovascular Diseases (NICVD), Karachi (ERC-33/2018). Verbal informed consent was obtained from all the patients regarding their participation in the study and publication of data while maintaining confidentiality and anonymity. Due to observational nature of the study, ERC waived the written consent and verbal consent were approved by the ERC.

\section{Consent for publication}

Not applicable.

\section{Competing interests}

All authors have no competing interests to disclose.

Received: 7 May 2021 Accepted: 21 October 2021

Published online: 29 October 2021

\section{References}

1. Levine GN, Bates ER, Blankenship JC, Bailey SR, Bittl JA, Cercek B, Chambers CE, Ellis SG, Guyton RA, Hollenberg SM, Khot UN (2016) 2015 ACC/ AHA/SCAl focused update on primary percutaneous coronary intervention for patients with ST-elevation myocardial infarction: an update of the 2011 ACCF/AHA/SCAl guideline for percutaneous coronary intervention and the 2013 ACCF/AHA guideline for the management of ST-elevation myocardial infarction. J Am Coll Cardiol 67(10):1235-1250

2. Ibanez B, James S, Agewall S, Antunes MJ, Bucciarelli-Ducci C, Bueno H, Caforio AL, Crea F, Goudevenos JA, Halvorsen S, Hindricks G (2017) 2017 ESC Guidelines for the management of acute myocardial infarction in patients presenting with ST-segment elevation: The Task Force for the management of acute myocardial infarction in patients presenting with ST-segment elevation of the European Society of Cardiology (ESC). Eur Heart J 39(2):119-177

3. Song JX, Zhu L, Lee CY, Ren H, Cao CF, Chen H (2016) Total ischemic time and outcomes for patients with ST-elevation myocardial infarction: does time of admission make a difference? J Geriatr Cardiol 13(8):658

4. Sardar MR, Dawn Abbott J (2016) Myocardial salvage and mortality in STEMI: a race against ischemic time. Catheter Cardiovasc Interv 87(7):1201-1202

5. Solhpour A, Chang KW, Arain SA, Balan P, Loghin C, McCarthy JJ, Vernon Anderson H, Smalling RW (2016) Ischemic time is a better predictor than door-to-balloon time for mortality and infarct size in ST-elevation myocardial infarction. Catheter Cardiovasc Interv 87(7):1194-1200

6. O'Gara PT, Kushner FG, Ascheim DD, Casey DE, Chung MK, De Lemos JA, Ettinger SM, Fang JC, Fesmire FM, Franklin BA, Granger CB (2013) 2013 ACCF/AHA guideline for the management of ST-elevation myocardial infarction: a report of the American College of Cardiology Foundation/ American Heart Association Task Force on Practice Guidelines. J Am Coll Cardiol 61(4):e78-140

7. Prasad A, Gersh BJ, Mehran R, Brodie BR, Brener SJ, Dizon JM, Lansky AJ, Witzenbichler B, Kornowski R, Guagliumi G, Dudek D (2015) Effect of ischemia duration and door-to-balloon time on myocardial perfusion in ST-segment elevation myocardial infarction: an analysis from HORIZONSAMI trial (Harmonizing Outcomes with Revascularization and Stents in Acute Myocardial Infarction). JACC Cardiovasc Interv 8(15):1966-1974

8. De Luca G, Suryapranata H, Ottervanger JP, Antman EM (2004) Time delay to treatment and mortality in primary angioplasty for acute myocardial infarction: every minute of delay counts. Circulation 109(10):1223-1225

9. Khalid U, Jneid H, Denktas AE (2017) The relationship between total ischemic time and mortality in patients with STEMI: every second counts. Cardiovasc Diagn Ther 7(Suppl 2):S119

10. Brodie BR, Gersh BJ, Stuckey T, Witzenbichler B, Guagliumi G, Peruga IZ, Dudek D, Grines CL, Cox D, Parise H, Prasad A (2010) When is door-to-balIoon time critical?: Analysis from the HORIZONS-AMI (Harmonizing outcomes with revascularization and stents in acute myocardial infarction) and CADILLAC (Controlled abciximab and device investigation to lower late angioplasty complications) trials. J Am Coll Cardiol 56(5):407-413 
11. Flynn A, Moscucci M, Share D, Smith D, LaLonde T, Changezi H, Riba A, Gurm HS (2010) Trends in door-to-balloon time and mortality in patients with ST-elevation myocardial infarction undergoing primary percutaneous coronary intervention. Arch Intern Med 170(20):1842-1849

12. Menees DS, Peterson ED, Wang Y, Curtis JP, Messenger JC, Rumsfeld JS, Gurm HS (2013) Door-to-balloon time and mortality among patients undergoing primary PCI. N Engl J Med 369(10):901-909

13. Chandrasekhar J, Marley P, Allada C, McGill D, O'Connor S, Rahman M, Tan $R$, Hosseiny AD, Shadbolt B, Farshid A (2017) Symptom-to-balloon time is a strong predictor of adverse events following primary percutaneous coronary intervention: results from the Australian Capital Territory PCI Registry. Heart Lung Circ 26(1):41-48

14. Doddipalli SR, Rajasekhar D, Vanajakshamma V, Naik KS (2018) Determinants of total ischemic time in primary percutaneous coronary interventions: a prospective analysis. Indian Heart J 70:S275-S279

15. Kim HK, Jeong MH, Ahn Y, Chae SC, Kim YJ, Hur SH, Seong IW, Hong TJ, Choi DH, Cho MC, Kim CJ (2017) Relationship between time to treatment and mortality among patients undergoing primary percutaneous coronary intervention according to Korea Acute Myocardial Infarction Registry. J Cardiol 69(1):377-382
16. Koifman E, Beigel R, lakobishvili Z, Shlomo N, Biton Y, Sabbag A, Asher E, Atar S, Gottlieb S, Alcalai R, Zahger D (2018) Impact of mobile intensive care unit use on total ischemic time and clinical outcomes in ST-elevation myocardial infarction patients - real-world data from the Acute Coronary Syndrome Israeli Survey. Eur Heart J Acute Cardiovasc Care 7(6):497-503

17. Flameng W, Lesaffre E, Vanhaecke J (1990) Determinants of infarct size in non-human primates. Basic Res Cardiol 85(4):392-403

18. Reimer KA, Vander Heide RS, Richard VJ (1993) Reperfusion in acute myocardial infarction: effect of timing and modulating factors in experimental models. Am J Cardiol 72(19):G13-21

19. Garcia-Dorado D, Théroux P, Elizaga J, Galiñanes M, Solares J, Riesgo M, Gomez MJ, Garcia-Dorado A, Fernandez AF (1987) Myocardial reperfusion in the pig heart model: infarct size and duration of coronary occlusion. Cardiovasc Res 21(7):537

\section{Publisher's Note}

Springer Nature remains neutral with regard to jurisdictional claims in published maps and institutional affiliations.

\section{Submit your manuscript to a SpringerOpen ${ }^{\circ}$ journal and benefit from:}

- Convenient online submission

- Rigorous peer review

- Open access: articles freely available online

- High visibility within the field

- Retaining the copyright to your article

Submit your next manuscript at $\boldsymbol{\nabla}$ springeropen.com 